(C2017, Elsevier. Licensed under the Creative Commons AttributionNonCommercial-NoDerivatives 4.0 International

http://creativecommons.org/about/downloads

(c) $(1) \Theta \Theta$ 


\section{Towards carborane-functionalized structures for the treatment of brain cancer}

Authors: Gianpiero Calabrese ${ }^{a}$ (corresponding author), Anis Daou ${ }^{a}$, Eugen Barbu ${ }^{\mathrm{b}}$, John Tsibouklis ${ }^{\mathrm{b}}$

Affiliations: "aSchool of Life Science, Pharmacy and Chemistry, Kingston University London, Penrhyn Road, Kingston-upon-Thames, Surrey, KT1 2EE, UK; ' School of Pharmacy and Biomedical Sciences, University of Portsmouth, Portsmouth, PO1 2DT, UK.

Corresponding author: Calabrese, G. (G.Calabrese@kingston.ac.uk); tel.: 02084179000

Keywords: BNCT, carboranes, brain cancer, boronated agents, clinical efficacy.

Teaser: The development of carborane derivatives with high cancer-cell targeting specificity is key to these materials fulfilling their promise as the clinical BNCT agents of the future.

Author biography See attached file 


\section{Abstract}

Boron Neutron Capture Therapy (BNCT) is a promising targeted chemo-radiotherapeutic technique for the management of invasive brain tumours, such as glioblastoma multiforme. Prerequisite to effective BNCT is the selective targeting of tumour cells with ${ }^{10} \mathrm{~B}$-rich therapeutic moieties. To this end, polyhedral boranes, especially carboranes, have received considerable attention since they combine high boron content, relative low toxicity and metabolic inertness. This article reviews progresses in the molecular design of recently investigated carborane derivatives in light of the widely accepted performance requirements for effective BNCT. 


\section{The principles of Boron Neutron Capture Therapy}

BNCT is a two-step targeted chemo-radiotherapeutic technique that involves the selective delivery of ${ }^{10} \mathrm{~B}$-rich agents to cancer cells for the purpose of their selective destruction through subsequent irradiation with lowenergy neutrons, which initiate highly localised nuclear fission reactions that do not damage surrounding tissue (Figure 1).
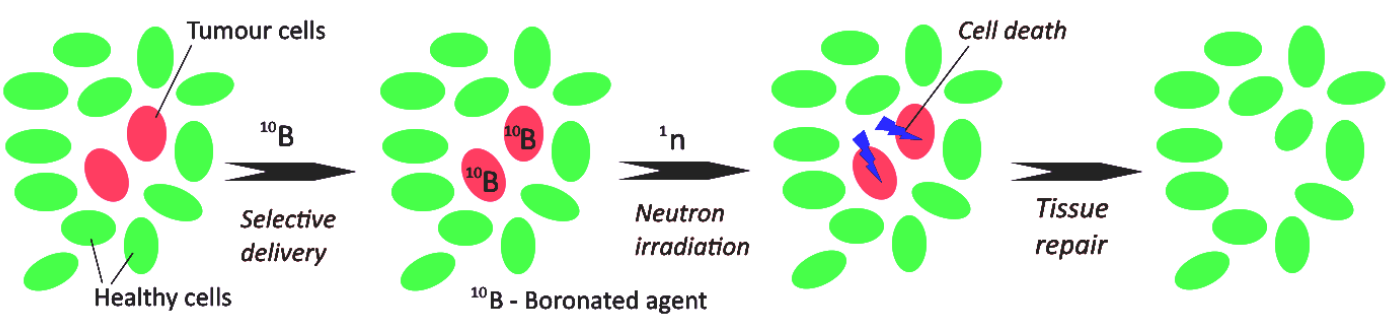

Figure 1.

Integral to successful BNCT is the selective uptake of a therapeutic dose of the boron-containing agent by cancer cells. At a neutron fluence of $10^{12}$ neutrons $/ \mathrm{cm}^{2}$, and ignoring the micro-distribution of the drug, this is calculated at $30 \mu \mathrm{g}$ of ${ }^{10} \mathrm{~B} / \mathrm{g}$ of tumour (about $10^{9}$ atoms of ${ }^{10} \mathrm{~B}$ per cell) [1]. In order to minimise damage to the vascular endothelial cells and to white matter, the ratios of tumour/blood and tumour/surrounding tissue concentrations must both be higher than 3:1 [2]. Monte Carlo simulations have shown that boron accumulated within the cell nucleus has little effect on neighbouring cells and it is more effective in inducing cell death (ca. 2.5x) than the same amount of boron distributed uniformly within the entire cell [3]. This suggests that the mechanism of neutron bombardment-initiated damage is determined by the intracellular location occupied by the boronated agent. Similarly, calculations have shown that boron localised at the cell surface has a ca. $10 \%$ lower killing effect than an equimolar quantity of boron that is uniformly distributed within the entire cell [3]. Irradiation of the localised boronated agent with a beam of thermal neutrons leads to each ${ }^{10} \mathrm{~B}$ atom capturing a neutron to form ${ }^{11} \mathrm{~B}^{*}$, which in turn undergoes nuclear fission to 
release the energy that induces localised tumour cell necrosis. Consequently, the nuclear reaction of ${ }^{10} \mathrm{~B}$ can effect the selective destruction of malignant tumour cells without compromising the surrounding healthy tissue. The probability of a nuclide capturing a neutron is enumerated by the "neutroncapture cross section" ( $\sigma_{\mathrm{th}}$, measured in barns; $1 \mathrm{~b}=10^{-24} \mathrm{~cm}^{2}$ ). Offering a good compromise between toxicity and stability, ${ }^{10} \mathrm{~B}$ is characterised by $\sigma_{\mathrm{th}}=$ $3838 \mathrm{~b}$ [4]. As compared with X-ray methods, the use of neutron beams is preferred for treatments involving hypoxic cells [5] since the oxygen enhancement ratio (the ratio of radiation doses required to effect the same rate of cell death under oxic as under hypoxic conditions) of neutrons is 1.6 which is lower than that of X-rays (2.5 to 3.0).

The interaction between neutrons and ${ }^{10} \mathrm{~B}$ nuclei generates recoiling ${ }^{7} \mathrm{Li}$ nuclei and $\alpha$-particles (also termed Linear Energy Transfer (LET) radiation), which are highly efficient in effecting cell death [6]. Since a-particles are equally lethal to hypoxic or oxygenated malignant cells as they are to surrounding tissue, in order to maximise the relative biological effectiveness the cytocidal effects of the BNCT capture reaction must occur primarily in malignant cells that have preferentially accumulated therapeutically useful amounts of ${ }^{10} \mathrm{~B}$. Consequent to the short path lengths $(4.5$ to $10 \mu \mathrm{m})$ of LET, the lethal effect is confined to the host cell [7]. Inevitable proton capture reactions that involve ${ }^{1} \mathrm{H}$ and ${ }^{14} \mathrm{~N}$ atoms produce $\mathrm{y}$-rays and protons, respectively, but the $\sigma_{\text {th }}$ values of these nuclei are too small to be of significance in the therapy of cancer [8]. Because of their greater capability to penetrate tissue, epithermal neutrons have been replacing thermal neutrons thermal neutrons are unable to act on tumours located below the tissue surface because of scattering effects. Epithermal neutrons, which are more energetic ( $0.5 \mathrm{eV}-1.0 \mathrm{keV}$ range) than thermal neutrons, do not suffer from the disadvantages of $\mathrm{H}$-recoil processes and consequently allow capture reactions to occur at some distance within the tissue: epithermal neutrons are progressively slowed into thermal neutrons through heat-releasing interactions with the hydrogen atom constituents of biological tissue that do not caused damage to biological tissue [9] 


\section{Applications and limitations of BNCT}

Although there has been interest in the application of BNCT for the treatment of skin [10] and liver [11] tumours, most studies to date have been focused on the treatment of brain tumours, especially glioblastoma multiforme (GBM) [12]; characterised by rapid regeneration of tumour cells and highly efficient DNA repair mechanisms, the condition is intrinsically resistant to treatment $[13,14]$. Since BNCT is associated with the induction of sublethal damage and potentially lethal damage to a non-repairable extent, it has been argued that the technique may act in synergy with surgery [15].

The multitude of performance requirements that ${ }^{10} \mathrm{~B}$-containing agents need to satisfy is reflected in the very small number of compounds that have been tested in the clinic. The limited clinical success of BNCT has been attributed to the: absence of sound procedures for the prediction and estimation of radiobiological effectiveness; inefficient methods for the optimization of drug delivery [16] and dosimetry [17]; random distribution and subcellular localisation of the ${ }^{10} \mathrm{~B}$-containing agents; and, limited availability of suitable neutron sources $[18,19]$. Key examples of clinical trials for the treatment of GBM by BNCT have been presented by Hosmane et al.[19]

\section{BNCT agents}

It has been argued [2] that an ideal BNCT agent should: be systemically non-toxic; be selective in targeting tumour cells (ideally accumulating within specified subcellular structures); persist intracellularly for a period of time that is consistent with the practicalities of the irradiation protocol; deliver the therapeutically optimal amount of $\sim 10^{9}{ }^{10} \mathrm{~B}$ atoms/cell; persist at tumour/normal tissues and tumour/blood ratios that are higher than $3: 1$ and 5:1, respectively; and, be capable of crossing biological membranes (most importantly, the blood brain barrier). To this end, polyhedral boranes 
have received considerable attention as the molecular moieties of choice for the development of therapeutic agents [20]. Among these, carboranes [21] (icosahedral dicarba-closo-dodecaboranes, $\mathrm{C}_{2} \mathrm{~B}_{10} \mathrm{H}_{12}$; the focus of this review) are of particular interest since their high ${ }^{10} \mathrm{~B}$ content is combined with good catabolic stability and low toxicity. Also, these materials are amenable to fine tuning through chemical functionalization at each vertex by means of well established chemical methodologies, which have been reviewed elsewhere $[22,23]$.

\section{Historical perspective: a promising start}

Attempts have been made to classify boronated agents according to key biological properties [24] but the most widely used system for their classification is chronological. Boron compounds are grouped into three generations: the first generation includes water-soluble salts of inorganic borates; the second generation reflects the introduction of polyhedral boranes; and the third generation encompasses agents that exploit the biochemical pathways through which boronated biomolecular analogues may be accumulated in subcellular structures.

The first generation of BNCT agents included sodium borates [25], such as borax and pentaborate, and boric acid. These agents presented a lack of selectivity, little persistence in tumour cells and low boron to tumour concentration ratio, which led to their failure, in the 1950s, to progress through clinical trials [24]. Consequent to the observation that paracarboxyphenylboronic acid (PCPB) [26] is not metabolized by the body, and is excreted unchanged through urine, this material was proposed as a candidate agent for BNCT. In a parallel development, para-borophenylalanine (BPA; compound 1, Figure 2), a material synthesised by Snyder et al. [27] presented another BNCT candidate material due to its structural similarity to phenylalanine (compound 2, Figure 2). 


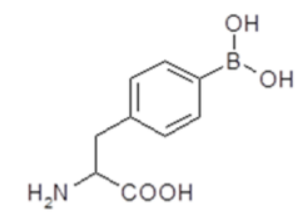

1

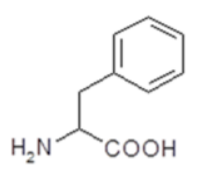

2
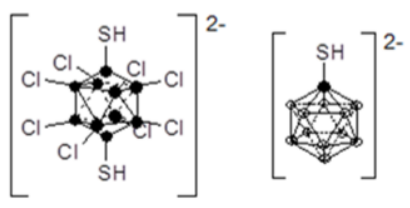

$$
\bullet=\mathrm{B}
$$

$\circ=\mathrm{BH}$

3

4

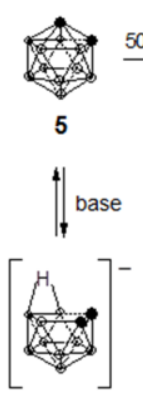

8

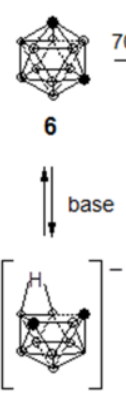

9
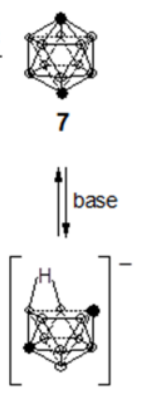

10

Figure 2.

The use of BPA is associated with favourable tumour/blood ratios, but it was not until the early 1980s that Mishima [28], taking advantage of BPA's structural similarity to melanin precursors, started a programme of research on the applications of BPA in the treatment of melanomas. By the early 1990s Coderre et al. [29] had begun to use BPA for the treatment of brain tumours.

A major development in the chemistry of boron is represented by the discovery, by Hawthorne et al. [30], of the polyhedral borane anions decahydrodecaborate $\left(\left[\mathrm{B}_{10} \mathrm{H}_{10}\right]^{2-}\right)$ and dodecahydrododecaborate $\left(\left[\mathrm{B}_{12} \mathrm{H}_{12}\right]^{2-}\right)$. Consequent to their aromatic-like nature, these non-planar compounds display remarkable chemical stability. Sodium decahydrodecaborate $\left(\mathrm{Na}_{2} \mathrm{~B}_{10} \mathrm{H}_{10}\right.$; GB-10) was recognised immediately as a potential clinical agent for BNCT, since it is less toxic than boric acid (respectively, for GB-10 and boric acid, $L D_{50}=1.04$ and $2.11 \mathrm{~g} / \mathrm{kg}$ of body weight) and it presents more favourable tumour/normal cells concentration ratios [31]. This molecule, however, did not meet its promise in clinical tests involving humans, which in 
turn had significant implications for the direction of BNCT research. The negative results from these trials revealed the sensitivity of the vascular endothelium to LET particles and highlighted the significance of boron concentration in blood during irradiation [32].

Screening experiments [33] designed to select drugs that give favourable tumour/blood concentration ratios identified the selective tumourcell uptake of sodium dimercaptooctachlorodecaborate $\left(1,10-\mathrm{Na}_{2} \mathrm{~B}_{10} \mathrm{Cl}_{8}(\mathrm{SH})_{2}\right.$; compound 3, Figure 2) and sodium mercaptoundecahydrododecaborate (BSH; compound 4, Figure 2). The impetus for further studies was provided by speculation, at the time, that the capability to recognize tumour cells and to promote accumulation may be inherent to the boron cluster structure, or may be linked to ionic charge, or to a specific interaction with certain proteins. The associated research efforts resulted in a third generation of boron compounds, which have been the primary focus of research over the last two decades. Boron compounds of this generation are designed such that they are rendered capable of reaching and binding to tumour cell receptors efficiently and selectively. Molecular design strategies have evolved to include the selective targeting of epidermal growth factor receptor, mitochondria, lysosomes, and tumour cell nuclei [34,35]. Integral to molecular design considerations has been the effect of the BBB on the transport of the active ingredient to the brain. The assumption that the BBB becomes permeable to therapeutic agents due to the leaky vasculature of brain tumours was quashed by the observation that isolated clusters of tumour cells, protected by the normal BBB, allow tumour reoccurrence [36].

From this generation of molecules, two have been advanced to the clinical stages of research, namely: BPA and BSH [37]. BPA has been evaluated as an agent for the treatment of melanomas [38], gliomas, sarcomas [39], and meningiomas [40]; most commonly as a complex of fructose (BPA-F). Evidence has been presented that BPA- $F$ is taken up through the metabolic pathways of the tumour, and also that it displays highly selective accumulation in tumours, low toxicity, few side effects, and, most importantly, that it is capable of crossing the BBB [41]. BPA-F has been shown to achieve tumour/blood and tumour/brain concentrations ratios of $c a$. 3.5/1 in 9L gliosarcoma (rat model) [42]; cell ablation has been investigated 
[43]. Several studies have been carried out on the intracellular distribution of BPA and according to Nguyen et al. [44] BPA accumulates prevalently in the cytosol but also in the nucleus. In an effort to improve the absolute and relative uptakes of boron in gliomas, the effects of dose and infusion time of BPA on the selectivity of delivery have been investigated [45]. The use of BPA allowed researchers to access tumour boron levels of $70 \mu \mathrm{g}{ }^{10} \mathrm{~B} / \mathrm{g}$ of tumour mass; improvement in therapeutic gain were achieved either by increasing the concentration of boron within the tumour or by increasing the tumour/blood concentration ratio [46]. The route and the administered dose are known to influence therapeutic gain [47], as demonstrated by studies on the pharmacokinetics and pharmacodynamics of BPA [48]. The chemistry of BPA has been reviewed by Sivaev and Bregadze [49].

$\mathrm{BSH}$ is a small hydrophilic anion, which in contrast to BPA, does not cross the BBB [50]. Used in infusion for the treatment of GBM, BSH has been shown to be not toxic and to be taken up by the tumour in reasonable amounts (tumour/brain ratio $>3 / 1$; tumour/blood ratio 0.9/1 - 2.5/1) [51]. Slow continuous intravenous infusion was identified as a safer and more efficient means of achieving a high concentration of boron. This technique leads to $\mathrm{BSH}$ uptake in malignant gliomas that is about three times higher than that in low grade gliomas [51]. The clinical application of $\mathrm{BSH}$ is generally associated with Hatanaka [52] and Nakagawa [53], who concentrated their efforts in the intracarotidal injection of BSH (typically $30-80 \mathrm{mg} / \mathrm{kg}$ of body weight). Tumour sampling after neutron irradiation indicated a high presence of $\mathrm{BSH}$ (up to 60 $\mu \mathrm{g}$ of ${ }^{10} \mathrm{~B} / \mathrm{g}$ of tumour). Hatanaka's clinical research resulted in the successful treatment of grade III and IV gliomas, with several long-term survivors, including a male patient who survived for more than 24 years [53]. Hatanaka's pioneering work led to many clinical BNCT investigations of $\mathrm{BSH}$ as a treatment for GBM [54-56]. The work has been extended to a study that involved the co-administration of BSH with BPA [57]. 


\section{Carboranes}

Carboranes are isoelectronic and isostructural with the dodecahydrododecarboronate $\left(\mathrm{B}_{12} \mathrm{H}_{12}\right)^{2-}$ anion and present aromatic behaviour $[21,58]$. The neutral lipophilic icosahedral dicarba-closododecarboranes $\left(\mathrm{C}_{2} \mathrm{~B}_{10} \mathrm{H}_{12}\right)$, whose first synthesis was reported independently by workers in the USA [59] and in the former USSR [60], exist in three isomeric forms: ortho (compound 5), meta (compound 6) and para (compound 7); Figure 2.

The carborane structure consists of two carbon and ten boron atoms that are arranged in an icosahedral geometry in which both carbon and boron are hexacoordinate [61]. Owing to its lipophilic nature, the ortho isomer is the regarded as the moiety of choice for the molecular design of structures that may be capable of crossing the BBB [62]. Carboranes are readily amenable to functionalisation. The boron vertexes are able to participate in electrophilic substitution reactions $[63,64]$, such as halogenation. Additionally, protons on carbon atoms may be abstracted by a strong base $\left(\mathrm{p} K_{\mathrm{a}}(\right.$ ortho $)=23.3, \mathrm{p} K_{\mathrm{a}}$ $($ meta $)=27.9, \mathrm{p} K_{\mathrm{a}}$ (para) $=30.0$ - Streitwieser's scale) [65] to form carbon nucleophiles that can be utilised to create $C-C$ linkages $[66,67]$. Treatment with a strong base allows the ready conversion of any of the isomeric forms of closo-carboranes into the corresponding hydrophilic nido-carboranes 8,9 , and 10 (Figure 2) by means of a deboronation reaction [68]. While the isomerization reaction of carboranes is not reversible, the transformation of nido-carborane to the corresponding closo-carborane is possible via a capping reaction [69]. Closo-carboranes have been investigated widely because of their high boron content and favourable pharmacokinetic properties, which altogether have rendered them promising candidate agents for use in medicinal chemistry. 


\section{Carborane chemistry: the search continues}

The significant interest in the synthesis of boronated analogues of biomolecules is consequent to the quest for therapeutic compounds with a capability to accumulate in subcellular structures. To this end, efforts towards the design of carboranyl compounds have concentrated on the mimicing of cellular building blocks (amino acids, sugars, etc.), such as to grant to boron access to cells via normal transport pathways as is exemplified by the classes of carboranyl compounds reviewed below.

\section{Amino acids}

Boron-containing amino acids have been investigated for their potential as BNCT pharmacophores. The observation by Endou and Kinai [70] that Lamino acid transport to the tumour tissue site is essential for tumour cell growth rationalised the synthesis of boron-containing alpha-amino acids, such as BPA and o-carboranyl-glycine [71]. The range of synthetic congeners has been extended by Brattsev [72] to ortho-carboranylalanine (CBA; compound 11; Figure 3). To the same end, Soloway [73] proposed a more convenient route involving the phase-transfer alkylation of commercial $N$ (diphenylmethylene) aminoacetonitrile with propargyl bromide, followed by the boronation of the resulting product with decacarborane-acenitrile complex and subsequent hydrolysis. The same synthetic route has been employed for the preparation of para-(ortho-carboran-1-yl)-phenylalanine (CBPA; compound 12) and $O$-(ortho-carboran-1-ylmethyl)-tyrosine (CBT; compound 13; Figure 3). Encouraging in vitro results prompted the in vivo testing of these molecules, which at respective tumour/blood concentration ratios of ca. 1.0 and 1.4 did not meet the performance requirements for further evaluation [74]. As a consequence of the discovery that the L-isomer of BPA accumulates selectively in melanoma cells, enantiomerically pure L-CBA was prepared [75], but this material has not been assessed in the clinic because the inherent boron tumour/healthy cells concentration ratio is not within the therapeutically useful range. 


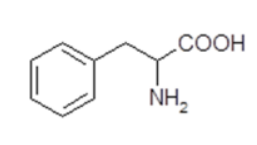

2

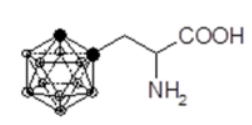

11

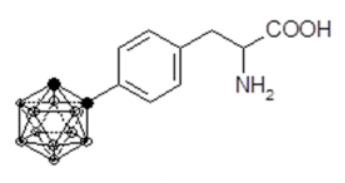

12

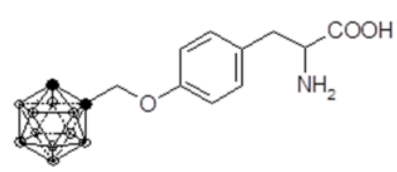

13

Figure 3.

Morris et al. [76] evaluated the effect of L-BPA prescription dose on the central nervous system (CNS) of the rat model and concluded that a dose of $1600 \mathrm{mg} \mathrm{L-BPA} / \mathrm{kg}$ is required to optimise the healthy tissue to blood ratio of boron concentration [77]. Efforts towards the optimisation of solubility in serum are informed by earlier attempts towards the improvement of the aqueous solubility of carboranyl aminoacids [71,78]. Since human thymidine kinase 1 (hTK1) is expressed in proliferating cells, Hasabelnaby et al. [79] proposed the use of carrier-linked prodrugs of 3-carboranyl thymidine [80]. Another approach towards the incorporation of boron into tumour-seeking molecules has been explored by the ring opening of cyclic oxonium derivatives of boron hydrides by means of the action of a nucleophilic agent $[81,82]$.

In common with naturally occurring amino acids, synthetic structures that combine R-amino acids and amino-boronic acids have been suggested as potential building blocks for BNCT [83,84], but the therapeutic promise of such compounds is yet to be demonstrated. Although the amount of research effort invested towards the development of new boronated amino acids has slowed considerably over the last decade, the approach remains validated by 
the promise of transport across biological barriers, such as the BBB, by dedicated carrier-mediated influx.

\section{Amines and amides}

The observation that organoboron compounds inhibit the $20 \mathrm{~S}$ proteasome [85], and also some enzymes such as lipases [86], has provided the impetus for the chemical synthesis and biological evaluation of many boronated amines. Synthetic methodologies towards these materials commonly involve a metal-halogen exchange reaction between an organometallic intermediate and an aryl halide-functionalised chiral amine [85]. To ameliorate cytotoxicity and to effect increased boron concentration at tumour cells, Lee et al. [87] have suggested an approach that involves the fine-tuning of the polarity of molecules through the manipulation of their capability to participate in $\mathrm{N}-\mathrm{H}-\mathrm{O}$ bonding. The approach led to compounds that exhibit low cytotoxicity $\left(\mathrm{IC}_{50}\right.$ in the range 0.2-0.7 $\left.\mathrm{mM}\right)$ and which effect in cancer cells boron concentrations that are higher than that achieved with the current benchmark material (BPA). The same investigations indicated that owing to the extend of $\mathrm{H}$-bonding interactions these compounds are more stable than their tertiary amine structure would suggest.

\section{Carbohydrates}

Boronated glyco-conjugate derivatives, such as glycosides, have attracted significant interest as potential vehicles for the delivery of boron [88], since their precursor glyco-conjugates are important in several biological processes that include cell growth, intercellular communication and intracellular recognition processes [89,90]. Glycoproteins-based targeting is guided by carbohydrate receptor-specific sites at the cell surface and by the expression of lectins at tumour cells [91]. Boronated glyco-conjugate formation is normally facilitated by glycosidic bonds between the carborane unit and the carbohydrate moiety [92]. To impart water solubility to such conjugates [88], the hydrophilic-lipophilic balance of the molecule may be adjusted by elongating the hydroxyl group-decorated carbohydrate moiety. An alternative approach to the synthesis of carboranyl carbohydrates involves the 
in situ formation of the boron cage. By means of this methodology Tietze et al.[93] prepared a series of carboranyl glycosides which have shown promise in tests involving melanoma cell lines (B-16) and rat glioma cells (C6), but in vivo tests demonstrated that the concentration of these compounds in blood was maintained at levels that are unacceptably high for meaningful use in therapy.

Since this class of compounds has been studied widely and because glucose uptake and glycolytic metabolism are amplified in most tumors, this class of compounds merits further investigations.

\section{Nucleic bases}

The observation that boronated nucleosides are retained in tumour cells due to their amenability to 5'-monophosphorylation by thymidine kinase 1 and deoxycytidine kinase has provided the driving force for the synthesis of boronated nucleic acids for BNCT applications [94,95]. Lesnikowski et al.[96] have argued that the performance requirements that inform the molecular design of such molecular structures are the high tagging efficiency of ${ }^{10} \mathrm{~B}$ to tumour cells, the improved lipophilicity of the compound as compared with the precursor nucleoside, and the efficacy of intracellular uptake. To this end, the same workers [96] suggested the addition of a linker between the carboranyl moiety and the 5-position of the uracil group and also proposed that nucleotides are used in conjunction with oligomers, as this compilation imparts resistance to enzymatic digestion, increases lipophilicity and promotes the formation of a stable duplex molecule within the oligonucleotide chain [96].

Since negatively charged cluster have been shown to adversely influence the ability of nucleosides to cross biological barriers, closocarboranes have received more attention than nido-carboranes [97]. Two main approaches have been adopted in molecular design: the first links the carborane to the ribose portion of the nucleoside, and the second attaches it to the base portion. Because of the lack of selective uptake presented by these compounds, and because of the narrow window of substrate modifications that the enzymes involved in DNA synthesis are able to accept, there are only a few examples of nucleosides bearing a carborane at the ribose site. Nucleosides bearing a substituent at the 5-position (e.g. 5-iodo or 
5-bromo-2'deoxyuridine) are very good substrates for enzymes involved in DNA synthesis, and are able to replace thymidine during this process [98]. Schinazi et al. [99] and Yamamoto et al. [100] respectively synthesised compounds 14 and 22 (Figure 4) and evaluated them in vitro and in vivo. Compounds 22 effected increased survival in mice, while studies involving enzymes suggested that the cellular uptake of 22 may be mediated by a nucleoside base transporter.
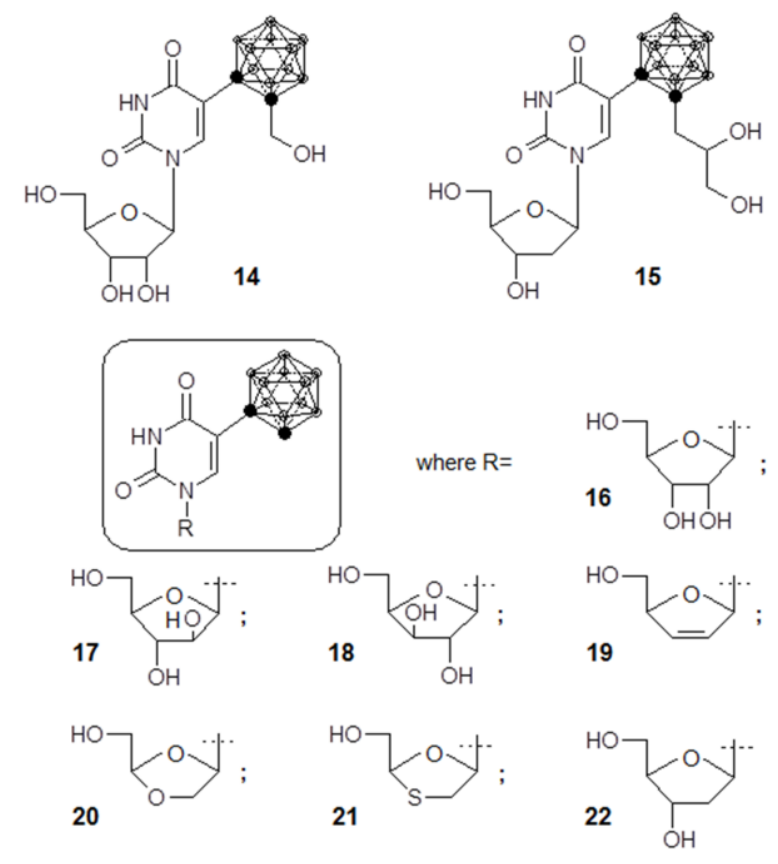

Figure 4.

Towards the improvement of the targeting specificity of boron compounds [101], the use of boron-rich carboranyl pyrazole-pyrimidines is reported through tests involving human cell lines to afford improved in vitro binding affinity.

Carborane-decorated pyrimidine rings are known to combine high boron content with good hydrolytic stability. In parallel, quinazolines, which may be regarded as hydrophobic analogues of pyrimidines, are known to display high affinity for the nucleic acids present in tumour cells [102]. Zhou et al. [103] have shown that hydrolytic stability is influenced by the number of 
hydroxyl-boryl groups in the molecular structure and that the biochemical properties of such compounds are highly sensitive to the presence of bulky aromatic groups. On the basis of this work it has been proposed that the carborane cage may be preferentially linked to the quinazoline group via a thioester linker [104].

The involvement of nucleic bases in cell processes and their associated ease of uptake by means of dedicated transport systems render these materials candidate carriers of boron for BNCT. However, since enzymes involved in the synthesis of DNA operate within the strict confines of substrate recognition, considerable research effort must be directed towards the establishment of the rules of molecular design.

\section{Triazine derivatives}

Several studies have utilised the synthetic versatility of the nucleophilic 1,3,5triazine ring for the preparation of BNCT agents. Ortho-carboranylthiolatesubstituted 1,3,5-triazines have been synthesised by the research group led by Lee [105], who through the introduction of a further molecular moiety effected improved biological activity through the bestowment of increased aqueous solubility to the structure. Preliminary in vitro studies indicated that many of these triazines effect the highly efficient accumulation of boron to B16 melanoma cells but are excessively cytotoxic.

\section{Porphyrins and phthalocyanines}

Dependent upon molecular structure, porphyrins have been shown to accumulate into the cytoplasm or at subcellular organelles (mitochondria, lysosomes, the Golgi apparatus, the endoplasmic reticulum or, in some cases, the nucleus) [106]. This property, coupled with low dark toxicity and amenability to activation by red light, renders porphyrins useful photosensitizers for applications in photodynamic therapy (PDT): upon exposure to red light they produce singlet oxygen [107], triggering mechanisms of cell death by necrosis and/or apoptosis [108]. Studies by Dass et al. [109] and also by Keefe et al. [110] have shown that porphyrins are taken up preferentially by tumours where they become accumulated and persist for prolonged periods of time. 
The use of porphyrins in BNCT, first proposed by Dougherty [111], led to investigations of means for the attachment of porphyrins to boron cages such that targeting specificity may be achieved [112]. One such strategy exploits variations in the expression of High- and Low-Density Lipoprotein (respectively, HDL and LDL). To assess in vivo transport, Polo et al. [113] attached hematoporphyrins to both HDL and LDL. Further studies provided evidence for the LDL receptor-mediated uptake of benzoporphyrin derivatives, but also suggested that the associated acetylation of LDL prevents cellular accumulation [114]. Towards the design of a molecular structure that anchors readily to biological substrates and is capable of inducing damage to DNA and RNA, Eason et al. [115] considered the derivatives of an amphiphilic closocarboranyl-porphyrin functionalised at opposite ends of the with a quaternary ammonium functionality and a negatively charged phosphonate water solubilizing group.

The synthesis of boronated porphyrins may be achieved by either condensing boronated aldehydic compounds with pyrrole, or by attaching boron moieties to the porphyrinic rings. The former approach has been used, by Haushalter et al. [116] for the first synthesis of a carboranyl-containing porphyrin, while the latter method is sufficiently versatile to be used with many functional groups, including esters, amides or double bonds. Carborane moieties may be easily transformed into their corresponding nido-form, conferring increased solubility in aqueous media to the resulting boronated porphyrin. Efforts towards the synthesis of boronated porphyrins have been reviewed by Pietrangeli et al. [117] Although many boronated porphyrins have been prepared to date, only a few have reached the clinic, primarily because of the need for a better understanding of their mechanism of tissue-selectivity, retention and biochemical action [106]. Tested in rats bearing C6 cerebral gliomas, the tetrakis-carborane-carboxylate ester of 2,4-bis-( $\alpha, \beta$ dihydroxyethyl) deuterioporphyrin IX (BOPP, compound 23, Figure 5) at 48 hours after administration (100 mg/kg of body weight) exhibited tumour/normal brain ratios of $400: 1$ and tumour/blood ratios of 11:1 [118]. Infusion of BOPP in the RG2 rat glioma model at $12 \mathrm{mg} / \mathrm{kg}$ of body weight, showed a lower, but still favourable, tumour/normal brain ratio of $13: 1$ and a tumour/blood ratio of 6:1 [119]. Munday et al. [120] identified functional mitochondria as the major in 
vivo cellular target of BOPP after uptake and photo activation. These results however could not be replicated in a Phase I clinical trial: BOPP could not deliver to the tumour a therapeutic amount of boron in patients suffering from GBM, while its toxicity limited considerably the dose that could be administered.

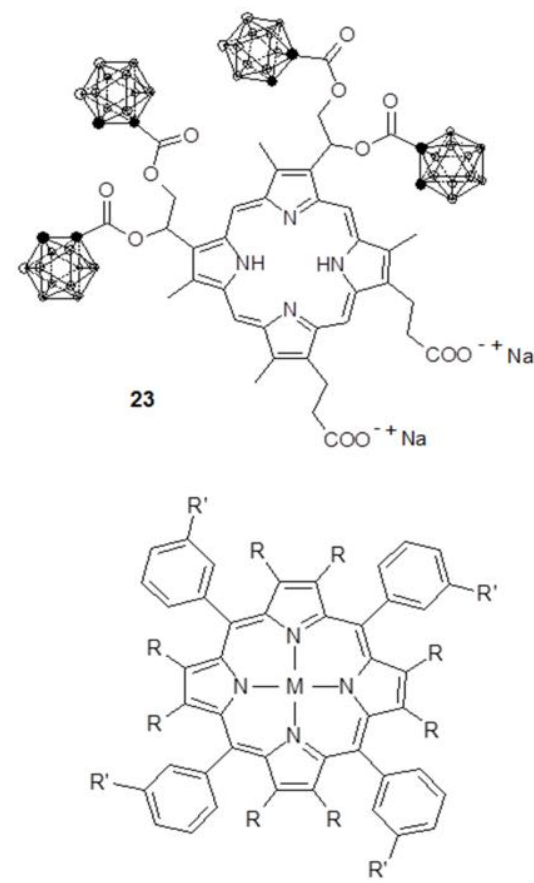

25: NiTCP, $\mathrm{M}=\mathrm{Ni}, \mathrm{R}=\mathrm{CH}_{2} \mathrm{CO}_{2} \mathrm{CH}_{3}, \mathrm{R}^{\prime}=\mathrm{OCH}_{2} \mathrm{C}_{2} \mathrm{~B}_{10} \mathrm{H}_{11}$ 26: $\mathrm{NiTCPH}, \mathrm{M}=\mathrm{Ni}, \mathrm{R}=\mathrm{H}, \mathrm{R}^{\prime}=\mathrm{OCH}_{2} \mathrm{C}_{2} \mathrm{~B}_{10} \mathrm{H}_{11}$ 27: NiNTCPH, M $=\mathrm{Ni}, \mathrm{R}=\mathrm{H}, \mathrm{R}^{\prime}=\mathrm{OCH}_{2} \mathrm{C}_{2} \mathrm{~B}_{9} \mathrm{H}_{11} \mathrm{~K}$ 28: CuTCP, $M=\mathrm{Cu}, \mathrm{R}=\mathrm{CH}_{2} \mathrm{CO}_{2} \mathrm{CH}_{3}, \mathrm{R}^{\prime}=\mathrm{OCH}_{2} \mathrm{C}_{2} \mathrm{~B}_{10} \mathrm{H}_{11}$
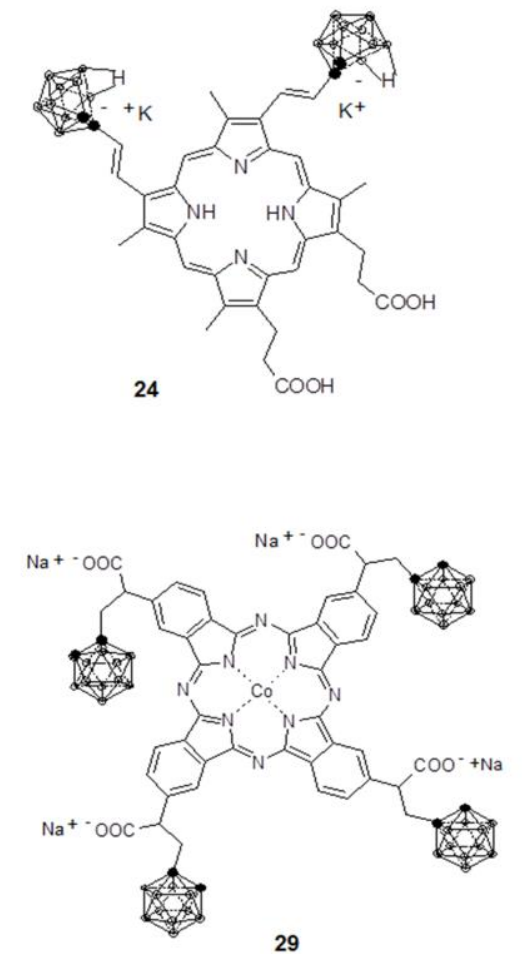

29

Figure 5.

Encouraging results have been obtained with porphyrins carrying two carborane cages per molecule, such as the carboranyl protoporphyrin IX derivative (PP-IX, compound 24, Figure 5), which at high doses gave tumour:normal brain ratios of 6:1 and tumour:blood ratios of 10:1 [121].

Since porphyrins are amenable to complex formation with certain metals $(\mathrm{Ni}, \mathrm{Cu}, \mathrm{Mn})$, their biodistribution may be readily evaluated through the use of radioactive chelate congeners. Representative examples of this class of compounds are the metal tetraphenylcarboranyl porphyrins (MTCP) (Figure 5) synthesised by Miura et al. [122]; nickel tetraphenylcarboranyl porphyrins (NiTCP) (compound 25), tetraphenylhydrocarboranyl porphyrin (NiTCPH) 
(compound 26), and copper tetraphenylcarboranyl porphyrin (CuTCP) (compound 28) are associated with favourable tumour/normal brain and tumour/blood concentration ratios. Notably, NiTCPH (compound 26) has been shown to deliver $100 \mu \mathrm{g}$ of ${ }^{10} \mathrm{~B} / \mathrm{g}$ of tumour tissue, and to achieve tumour/normal brain concentration ratios of 50:1 and tumour/blood concentration ratios $>500: 1$.

Vicente et al. [123] studied a 36 boron atom water-soluble mesosubstituted porphyrin $\left(\mathrm{H}_{2} \mathrm{TCP}\right)$, which at $100 \mu \mathrm{M}$ showed no significant cytotoxic effect against murine melanotic melanoma cells in the dark but upon irradiation with red light caused cell mortality at the $20 \mu \mathrm{M}$ level.

Owing to their structural analogy with porphyrins, some phthalocyanines have been investigated as potential boron carriers [124], as is exemplified by the boronated metal-phthalocyanine 73 prepared by Kahl et al. [125] (Figure 5).

\section{Delocalized lipophilic cations}

Several Delocalized Lipophilic Cations (DLC) are known to accumulate selectively in tumour cells [126]. These include the mitochondrial dye rhodamine 123, tri-phenyl-methyl-phosphonium (TPMP) iodide, and tetraphenylphosphonium (TTP) chloride. The DLC structure interacts selectively with tumour cells as a consequence of the $\sim 60 \mathrm{mV}$ difference between the mitochondrial transmembrane potential of healthy and cancer cells [127]. The resonance-stabilized positive charge of DLCs combined with their inherent lipophilicity, effect a significant decrease in the cost associated with the free energy change that accompanies the diffusion of DLCs through cell membranes, and lead to a $>100$ fold accumulation of DLCs in the mitochondrial matrix of tumour cells, in addition to the high difference ( $>5$ fold) in the cytoplasmic and extracellular concentrations [36]. Consequently, DLCs are considered to be promising carrier moieties for mitochondria-selective, target-specific boronated anticancer agents. The plasma membrane potential (typically $30-60 \mathrm{mV}$, negative inside) also drives the accumulation of cations into the cells where they are then further accumulated into mitochondria, with $90-95 \%$ of intracellular cations being localized in mitochondria [128]. 
Adams et al. [129] have synthesised a carboranyl derivative of dequalinium that exhibits in vitro tumour uptake and toxicology that are similar to those characterising its non-boronated analogue. In vitro, DEQ-B was seen to be taken up and retained in KB, F98 and C6 tumour cell lines, but not in the normal epithelial cell line CV1. At low concentrations, DEQ-B was shown to be less toxic in the normal cell line. The uptake, retention and toxicity of DEQ-B were found to be comparable with those of other non-boronated DLCs, such as dequalinium chloride, rhodamine 123 and tetraphenylphosphonium chloride [129].

The synthesis and preliminary in vitro evaluation have been reported[130] of 4-ortho- and 4-meta-carboranyl-N-(9-(diethylamino)-5Hbenzo[a]phenoxazin-5-ylidene) butanamide (30 and 31) and of the salts dequalinium bis-nido-carborane (32), rhodamine-123-nido-carborane (33) and tetraphenyl phosphonium nido-carborane (34); Figure 6.

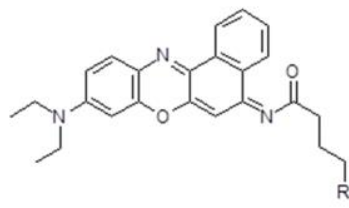

$30 \mathrm{R}=$ ortho-carborany $31 \mathrm{R}=$ meta carborany

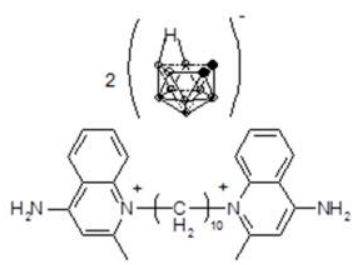

32

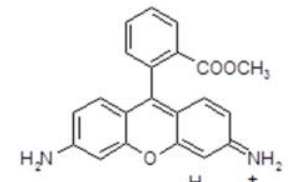

33

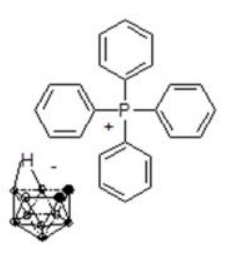

34

Figure 6. 
These compounds were tested in vitro against human prostate epithelial carcinoma (PC3) and normal (PNT2) cell lines, and the amount of ${ }^{10} \mathrm{~B}$ taken up by cells was evaluated by inductively coupled plasma-mass spectrometry (ICP-MS). Accumulation ratios (PC3/PNT2) were found to be 3.1 for compound 30, 2.2 for compound 31, 4.2 for compound 32, 3.0 for compound 33, and 3.1 for compound 34 [130]. All tested compounds facilitated the tumour-cell accumulation of therapeutically relevant concentrations of ${ }^{10} \mathrm{~B}$. Consistent with the expected increase in the membrane potential in the mitochondria of carcinoma cells, in all cases the percentage of ${ }^{10} \mathrm{~B}$ taken up by PC3 cells was somewhat higher than the corresponding uptake by PNT2 cells [130]. Compounds (Figure 6) that do not present a covalent link between the DLC and the boron moiety have afforded therapeutical amounts of boron intercellularly, indicating that a covalent bond may not be necessary [131]. It is possible that DLCs guide their boronated counter-ions to cancer cells. Alternatively, ionic boronated structure may have an inherent affinity for cancer cells. To further explore these findings, Tseligka et al. [132] tested several DLC-functionalized carborane compounds in cultures of normal (MRC-5, Vero), cancer (U-87 MG, HSC-3) and primary glioblastoma cancer stem cells (EGFR ${ }^{\text {pos }}, E G_{F R}{ }^{\text {neg }}$ ). The pharmacological anticancer profile of these compounds revealed: a) significant in vitro selectivity, marked by a $\sim 10 \times$ lower concentration needed to exert a cell growth-arrest effect on U-87 MG and HSC-3 than on MRC-5 and Vero; and, b) selective growth inhibition behaviour towards EGFR ${ }^{\text {pos }}$ and EGFR ${ }^{\text {neg }}$ cultures ( $>10 \times$ difference in potency) without the activation of apoptosis. Notably, and in marked contrast to cancer cells, normal cells are capable of recapitulating their full proliferation potential following exposure to DLC-carboranes. The pharmacological effects of DLC-carboranes have been unveiled by the same study to be elicited at the molecular level through activation of the p53/p21 axis [132].

Following in vivo studies that showed quick uptake, high selectivity (ca. $10 \times$ higher than the currently used BNCT agents) and significant retention of triphenylmethylphosphonium iodide in canine brain tumor, the group of Rendina [131] developed a series of water-soluble phosphonium salts containing carborane. The poor aqueous solubility of closo-carboranes led the 
group to investigate the deboronation and rearrangement of a closo-1,12dicarbadodecaborane to the zwitterionic nido-7,9-dicarbaundecaborane structure [133]. The work built on that of Hawthorne [134] who had demonstrated the improved water solubility of ionic carborane structures through investigations involving alkylphosphonium-closo-carborane salts. The promise of DLCs as an excellent means of imparting selectivity to boronated agents merits futher investigation, such that the relationships between chemical structure and biology activity are understood in sufficient detail to inform the optimisation strategies to molecular design.

\section{Existing drugs}

Several CNS depressants - including promazines, hydantoins and barbiturates - have been investigated as possible carriers of boron for BNCT. The interest in boronated promazines was first prompted by studies on the localization of chlorpromazine (CPZ) in melanoma-bearing rats [135]. This compound exhibited selective accumulation in tumours $(100 \mu \mathrm{g} / \mathrm{g}$ of tumour tissue, a tumour/normal tissue ratio $>15$ ) and a half-life of 10 days [135]. In the 1970s, Nakagawa et al. [136] prepared a boronated CPZ analogue by attaching a nine boron atom cage to the nitrogen of the aliphatic chain; but probably because this nitrogen atom is involved in the substrate recognition for the compound's intracellular transit, the results obtained were not very promising. Other boronated CPZ derivatives exhibited acceptable levels of toxicity but disappointing in vivo localization, which has been explained in terms of the accumulation of these chemicals into the liver [137].

Interest in the preparation of boronated barbiturates and hydantoins has been mainly fuelled by the observation that some of these compounds are able to enter the brain rapidly and achieve high tumour/normal brain concentration ratios. The first boronated barbiturates were synthesised in the 1970s, but it was not until 1998 that Wyzlic et al. [138] observed selective accumulation following the preparation of a boronated barbiturate and hydantoin. However, little evidence was provided to indicate that these compounds possess characteristics that are prerequisite to candidate molecules for clinical evaluation. 


\section{Organometallics}

Following the discovery of the antitumour activity of cisplatin (cis$\left.\mathrm{Cl}_{2} \mathrm{Pt}\left(\mathrm{NH}_{3}\right)_{2}\right)$, several metal-based compounds have been screened for their capability to target cancer cells. Bregadze et al. [139] and Gielen et al. [140] synthesised compounds 35, 36 and 37 (Figure 7), which have been tested in vitro against several human tumour cell lines, including: Caucasian breast adenocarcinoma (MCF-7); colon carcinoma (WiDr); breast carcinoma (EVSAT); ovarian carcinoma (IGROV); melanoma (M19 MEL), and renal cancer (A498). The in vitro activities of 35 and 36 against MCF-7 were found to be comparable with the activity of doxorubicin, and the activity of 37 to be superior to that of cisplatin; the in vivo testing of 36 on rats bearing murine leukaemia (L1210) led to one mouse being cured. A systematic study of the influence of substituents $R$ and $R^{\prime}$, presented in Figure 7 , found that the potency of agents is augmented if $R=n$-butyl.

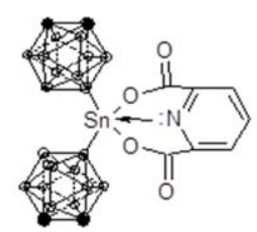

35

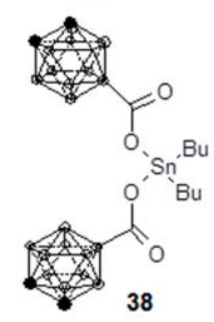

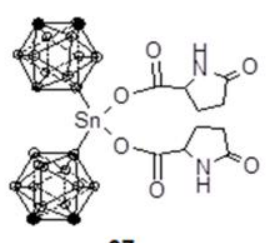

37

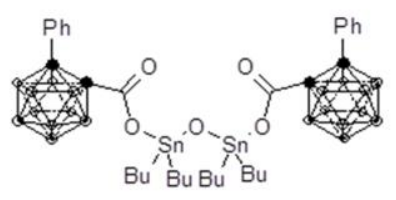

39

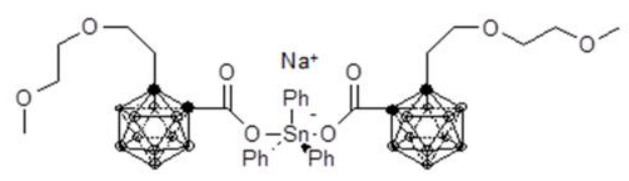

40

Figure 7. 
Tested against human cell lines in vitro, compounds 38,39 and 40, which had been synthesised by Tiekink and Bregadze [141,142], displayed therapeutic activities that were deemed to be at least comparable with those of cisplatin, carboplatin or methotrexate. Notably, the most water-soluble compound of the series, triphenylstannate sodium salt 40 , exhibits the highest cytotoxicity.

In general, issues of low aqueous solubility and high cytotoxicity, even in the absence of neutron irradiation, have hindered the application of carborane-functionalized platinum (II) complexes in BNCT[143,144].

In an effort to combine the potential advantages of the two main nuclides that are generally regarded as useful for applications in NCT, namely $B$ and $\mathrm{Gd}$, a complex (GdBLDL) which presents an o-carborane cage and an MRI-probe moiety, Gd-DOTA monoamide, has been synthesised [145], but the therapeutic promise of the material has yet to be evaluated.

\section{Concluding remarks}

To fulfil its promise as the treatment of choice for brain cancers, BNCT requires ${ }^{10} \mathrm{~B}$-rich drugs that can target selectively and accumulate preferentially in tumour cells. Although research efforts towards the design and synthesis of suitable candidates for BNCT have been considerable and span several decades, the multitude and complexity of the performance demands from such materials have acted co-operatively to impede progress. The advent of carborane chemistry has allowed the issue of achieving therapeutically useful concentrations of ${ }^{10} \mathrm{~B}$ in cancer tissue to be addressed and for methods to be developed towards the bestowment of target specificity. While both developments represent significant advances to BNCT chemistry, the issue of the efficient transport of the boronated active from the point of administration to the site of action, which is often complicated by biological barriers (the BBB being a case in point) represents a significant challenge that remains largely unaddressed. 


\section{Figures captions}

Figure 1. BNCT steps: selective delivery of ${ }^{10} \mathrm{~B}$-drugs to tumour cells is followed by irradiation with slow-moving neutrons $\left({ }^{1} n\right)$, leading to tissue repair.

Figure 2. Structures of L-para-borophenylalanine BPA (1), L-phenylalanine (2), dimercaptooctachlorodecaborate $1,10-\mathrm{B}_{10} \mathrm{Cl}_{8}(\mathrm{SH})_{2}{ }^{2-}$ anion (3) and mercaptoundecahydrododecaborate $(\mathrm{BSH})\left(\mathrm{B}_{12} \mathrm{H}_{11} \mathrm{SH}\right)^{2-}$ anion (4), ortho- (5), meta- (6) and para- (7) isomers of carboranes, and their interconversion.

Figure 3. Structures of L-phenylalanine (2), L-o-carboranylalanine (CBA; compound 11), L-p-(o-carboran-1-yl)-phenylalanine (CBPA; compound 12), and L-O-(o-carboran-1-ylmethyl)-tyrosine (CBT; compound 13).

Figure 4. Nucleosides and deoxynucleosides bearing a carboranyl moiety in 5-position.

Figure 5. Structures of boronated porphyrins BOPP (compound 23) and PP-IX (compound 24); metal tetraphenylcarboranyl porphyrins NiTCP (compound 25), NiTCPH (compound 26), NiNTCPH (compound 27) and CuTCP (compound 28); and carboranyl cobalt-phthalocyanine (compound 29).

Figure 6. Structures of closo-carboranyl derivatives of Nile Blue (compounds 30 and 31), and of the nido-carborane salts of dequalinium (compound 32), rhodamine-123 (compound 33) and tetraphenyl phosphonium (compound 34).

Figure 7. Carboranyl-organotin compounds that show anti-tumour activity.

\section{Glossary}

Epithermal neutrons: A neutron having energy in the range immediately above the thermal range, roughly between 0.02 and $100 \mathrm{eV}$.

Linear energy transfer: energy transfered to the material traversed per unit distance.

Neutron capture cross section: describes the likelihood of interaction between an incident neutron and a target nucleus; measured in barns (b).

Neutron fluence: measure of the intensity of neutron radiation as determined by the rate of flow of neutrons per area of tissue.

Oxygen enhancement ratio: the ratio of radiation doses required to effect the same rate of cell death under oxic as under hypoxic conditions.

Potentially lethal damage: DNA damage occurring due to irradiation. 
Relative biological effectiveness: the ratio of the doses required by two radiations to cause the same level of effect.

Sublethal damage: sublethal damage is not lethal to cells, but can interact with similar damage from further radiation treatment to produce lethal damage.

Thermal neutron: a neutron that is not bound within an atomic nucleus and that possesses an average kinetic energy of 0.025 electronvolts at room temperature.

\section{References}

[1] Hawthorne, M.F. (1998) New horizons for therapy based on the boron neutron capture reaction. Mol. Med. Today 4 (4), 174-181

[2] Sauerwein, W. et al. (1997) Considerations about specification and reporting of dose in BNCT. In Advances In Neutron Capture Therapy: Medicine And Physics. (Larsson, B. Crawford, J. and Weinrich, R. eds) pp. 531-534, Amsterdam, Elsevier

[3] Gabel, D. et al. (1987) The Monte Carlo simulation of the biological effect of the ${ }^{10} \mathrm{~B}(\mathrm{n}, \alpha){ }^{7} \mathrm{Li}$ reaction in cells and tissue and its implication for boron neutron capture therapy. Radiat. Res. 111, 25-36

[4] Sauerwein W. (1993) Principles and history of neutron capture therapy. Strahlenther. Onkol. 169, 1-6

[5] Raju MR. (1996) Particle radiotherapy: historical developments and current status. Radiat. Res. 145, 391-407

[6] Davis, M.A. and Little, J.B. (1970) Relative biological effectiveness of the ${ }^{10} \mathrm{~B}(\mathrm{n}, \alpha){ }^{7} \mathrm{Li}$ reaction in HeLa cells. Radiat. Res. 43, 534-553

[7] Schiffer, D. et al. (1998) Proliferative Properties of Malignant Brain Tumors. In Brain Tumor Invasion: Biological, Clinical And Therapeutic Considerations. (Mikkelsen, T. Bjerkvig, R Laerum, O.D. and Rosenblum, M.L. eds) pp. 161-184, Wiley-Blackwell

[8] Barth, R.F. et al. (1996) Boron neutron capture therapy of brain tumours: past history, current status, and future potential. Cancer Invest. 14 (6), 534-550

[9] Fairchild, R.G. and Bond, V.P. (1985) Cobalamin conjugates useful as imaging and therapeutic agents. Int. J. Radiat. Oncol., Biol., Phys. 11 (4), 831-840

[10] Mishima, Y. (1996) Selective Thermal Neutron Capture Therapy of Cancer Cells Using their Specific Metabolic Activities-Melanoma as Prototype. In Cancer Neutron Capture Therapy (Mishima, Y. ed) pp. 126 New York, Plenum Press

[11] Wilkinson, E. (2003) An out-of-body experience. Lancet Oncol. 4 (2), 64 
[12] Yamamoto, T. et al. (2008) Boron neutron capture therapy for glioblastoma. Cancer Lett. 262, 143-152

[13] Visser, O. et al. (2015). Survival of adults with primary malignant brain tumours in Europe; Results of the EUROCARE-5 study. Eur. J. Cancer. 51(15), 2231-2241

[14] Barth, R.F. et al. (2005) Boron Neutron Capture Therapy of Cancer: Currents Status and Future Prospects. Clin. Cancer Res. 11(11), 39874002

[15] Utsumi, H. et al. (1989) Sublethal and potential lethal damage repair on thermal neutron capture therapy. Pigm. Cell Res. 2, 337-342

[16] Calabrese, G. et al. (2012) The formulation of polyhedral boranes for the boron neutron capture therapy of cancer. Drug Discovery Today 17 (34), 153-159

[17] Munck af Rosenschöld, P.M. et al. (2004) Quality assurance of patient dosimetry in boron neutron capture therapy. Acta Oncol. 43 (4), 404-411

[18] Yongmao Z. (2009) Neutron Capture Therapy (NCT) \& In-Hospital Neutron Irradiator (IHNI)- a new technology on binary targeting radiation therapy of cancer. Engineering Sciences 7 (4), 1-21

[19] Hosmane, N.S. et al. (2012) Boron and Gadolinium Neutron Capture Therapy for Cancer Treatment, World Scientific Publishing Company

[20] Sivaev, I.B. and Bregadze, V.V. (2009) Polyhedral boranes for medical applications: current status and perspectives. Eur. J. Inorg. Chem. 11, 1433-1450

[21] Grimes, R.N. ed (2016) Carboranes, Academic Press, Elsevier

[22] Puga, A.V et al. (2009) From Mono- to Poly-Substituted Frameworks: A Way of Tuning the Acidic Character of $\mathrm{Cc}-\mathrm{H}$ in o-Carborane Derivatives. Chem. - Eur. J. 15(38), 9755-9763

[23] Teixidor, $\mathrm{F}$ et al. (2005) Are methyl groups electron-donating or electronwithdrawing in boron clusters? Permethylation of o-carborane. J. Am. Chem. Soc. 127(29), 10158-10159

[24] Hawthorne, M.F. and Lee, M.W. (2003) A critical assessment of boron target compounds for boron neutron capture therapy. J. Neuro-Oncol. 62, 33-45

[25] Farr, L.E. et al. (1954) Neutron capture therapy with boron in the treatment of glioblastoma multiforme. Am. J. Roentgenol. Radium Ther. Nucl. Med. 71, 279-291

[26] Soloway, A.H. et al. (1998) The chemistry of neutron capture therapy. Chem. Rev. 98, 1515-1562

[27] Snyder, H.R. et al. (1958) Synthesis of aromatic boronic acids. Aldehydo boronic acids and a boronic acid analog of tyrosine. J. Am. Chem. Soc. 80, 835-838

[28] Ichihashi, M. et al. (1982) Specific killing effect of ${ }^{10} \mathrm{~B}_{1}$-paraboronophenylalanine in thermal neutron capture therapy of malignant melanoma: in vitro radiobiological evaluation. J. Invest. Dermatol. 78, 215-218

[29] Coderre, J.A. et al. (1990) Selective delivery of boron by the melanin precursor analogue $p$-boronophenylalanine to tumors other than melanoma. Cancer Res. 50, 138-141

[30] Pitochelli, A.R. and Hawthorne, M.F. (1960) The isolation of the icosahedral $\mathrm{B}_{12} \mathrm{H}_{12}{ }^{2-}$ ion. J. Am. Chem. Soc. 82 (12), 3228-3229 
[31] Diaz, A. et al. (2002) Pharmacology studies of $\mathrm{Na}_{2}{ }^{10} \mathrm{~B}_{10} \mathrm{H}_{10}$ (GB-10) in human tumor patients. In Research And Development In Neutron Capture Therapy (Sauerwein, W. et al. eds) pp.8-13, Monduzzi Editore, Bologna

[32] Soloway, A.H. et al. (1961) Evaluation of boron compounds for use in neutron capture therapy of brain tumors. I. Animal investigations. J. Pharmacol. Exp. Ther. 134 (1), 117-122

[33] Goodman, J.H. et al. (2000) Boron neutron capture of brain tumours: biodistribution, pharmacokinetics, and radiation dosimetry of sodium borocaptate in patients with gliomas. Neurosurgery 47, 608-622

[34] Azab, A. K. et al. (2006) Chapter 5 - Boron neutron capture therapy In Studies in Inorganic Chemistry 22, 337-366

[35] Wu, G. et al. (2006). Boron containing macromolecules and nanovehicles as delivery agents for neutron capture therapy. Anticancer Agents Med. Chem. 6 (2), 167-184

[36] Don, A.S. and Hogg, P.J. (2004). Mitochondria as cancer drug targets. Trends Mol. Med. 10 (8), 372-378

[37] Nakagawa, Y. et al. (2009) Clinical results of BNCT for malignant brain tumors in children. Appl. Radiat. Isotop. 67, S27-S30

[38] Mitin, V.N. et al. (2009) Comparison of BNCT and GdNCT efficacy in treatment of canine cancer. Appl. Radiat. Isotop. 67 (7-8) S299-S301

[39] Pignol, J-P. et al. (1998) Selective delivery of ${ }^{10} \mathrm{~B}$ to soft tissue sarcoma using ${ }^{10} \mathrm{~B}$-L-borophenylalanine for boron neutron capture therapy. Br. J. Radiol. 71, 320-323

[40] Tamura, Y. et al. (2006) Boron neutron capture therapy for recurrent malignant meningioma. J. Neurosurg. 105, 898-903

[41] Wyzlic, I.M. et al. (1994) Strategies for the design and the synthesis of boronated nucleic and protein components as potential delivery agents for neutron capture therapy. Int. J. Radiat. Oncol. Biol. Phys. 28, 12031213

[42] Coderre, J.A. et al. (1994) Neutron capture therapy of the 9L gliosarcoma using the $\rho$-boronphenyalanine-fructose complex. Int. J. Radiat. Oncol. Biol. Phys. 30, 643-652

[43] Coderre, J.A. et al. (1994) Selective ablation of rat brain tumours by boron neutron-capture. Int. J. Radiat. Oncol. Biol. Phys. 28, 1067-1077

[44] Nguyen, T. et al. (1993) Intracellular distribution of various boron compounds for use in boron neutron capture therapy. Biochem. Pharmacol. 45 (1), 147-155

[45] Joel, D.D. et al. (1999) Effect of dose and infusion time on the delivery of p-boronophenylalanine for neutron capture therapy. J. Neuro-Oncol. 41, 213-221

[46] Coderre, J.A. et al. (1998) Boron Neutron Capture Therapy. In Textbook Of Radiation Oncology (Leibel, S. and Phillips, T. eds) pp. 1263-77, Philadelphia: W. B. Saunders Company

[47] Yang, W. et al. (1996) Enhanced delivery of boronophenylalanine for neutron capture by means of intracarotid injection and blood-brain barrier disruption. Neurosurgery 38, 985-992

[48] Cruickshank, G.S. et al. (2009) A cancer research UK pharmacokinetic study of BPA-mannitol in patients with high grade glioma to optimise 
uptake parameters for clinical trials of BNCT. Appl. Radiat. Isotop. 67, S31-33

[49] Sivaev, I.B. and Bragdze, V.I. (2008) L-4-Boronophenylalanine (all around the one molecule). ARKIVOC iv, 47-61

[50] Stragliotto, G. and Fankhauser, H. (1995) Biodistribution of boron sulfhydryl for boron neutron capture therapy in patients with intracranial tumours. Neurosurgery 36, 285-293

[51] Kageji, T. et al. (1997) Pharmacokinetics and boron uptake of BSH $\left(\mathrm{Na}_{2} \mathrm{~B}_{12} \mathrm{H}_{11} \mathrm{SH}\right)$ in patients with intracranial tumors. J. Neuro-Oncol. 33, 117-130

[52] Hatanaka, H. et al. (1986) Clinical experience of boron-neutron capture therapy for gliomas: a comparison with conventional chemo-immunoradio-therapy. In Boron Neutron Capture Therapy For Tumours (Hatanaka, H. ed) pp. 349-78 Niigata, Japan: Nishimura Co.

[53] Hatanaka, H. and Nakagawa, Y. (1994) Clinical results of long-surviving brain tumour patients who underwent boron capture therapy. Int. J. Radiat. Oncol. Biol. Phys. 28, 1061-1066

[54] Nakagawa, Y. (2002) Boron neutron capture therapy since 1968 in Japan. In Research And Development In Neutron Capture Therapy (Sauerwein, W. et al. eds) pp. 1061-4, Monduzzi Editore, Bologna

[55] Sauerwein, W. and Zurlo, A. (2002) The EORTC Boron Neutron Capture Therapy (BNCT) Group: achievements and future projects. Eur. J. Canc. 38, S31-S34

[56] Paquis, P. et al. (2002) Tissue uptake of BSH in patients with glioblastomas in the EORTC 11961 Phase I BNCT trial. In Research And Development In Neutron Capture Therapy (Sauerwein, W. et al. eds) pp. 1017-21, Monduzzi Editore, Bologna

[57] Barth, R.F. et al. (2000) Boron neutron capture therapy of brain tumors: enhanced survival and cure following blood-brain barrier disruption and intracarotid injection of sodium borocaptate and boronophenylalanine. Int. J. Radiat. Oncol. Biol. Phys. 47, 209-218

[58] Poater, J. et al. (2016) Huckel's Rule of Aromaticity Categorizes Aromatic closo Boron Hydride Clusters. Chem. - Eur. J. 22 (22), 74377443

[59] Heying, T.L. et al. (1963) A new series of organoboranes. I. Carboranes from the reaction of decaborane with acetylenic compounds. Inorg. Chem. 2 (6), 1089-1092

[60] Zakharkin, V.I. et al. (1963) Izv. Akad. Nauk. SSSR, ser. khim. 2069

[61] Bregadze, V.I. (1992) Dicarba-closo-dodecaboranes $\mathrm{C}_{2} \mathrm{~B}_{10} \mathrm{H}_{12}$ and their derivatives. Chem. Rev. 92 (2), 209-223

[62] Fauchére, J.L. et al. (1980) Unusually strong lipophilicity of 'fat' or 'super' amino-acids, including a new reference value for glycine Experientia 36, 1203-1204

[63] Puga, A.V. et al. (2009) lodinated ortho-Carboranes as Versatile Building Blocks to Design Intermolecular Interactions in Crystal Lattices. Chem. Eur. J. 15 (38), 9764-9772

[64] Olid, D. et al. (2013) Methods to produce B-C, B-P, B-N and B-S bonds in boron clusters. Chem. Soc. Rev. 42 (8), 3318-3336 
[65] Hermansson, K. et al. (1999) o-, m-, and p-carboranes and their anions: $\mathrm{Ab}$ initio calculations of structures, electron affinities, and acidities. Inorg. Chem. 38(26), 6039-6048

[66] Oliva, J.M. et al. (2005) Strikingly long C center dot center dot center dot $\mathrm{C}$ distances in 1,2-disubstituted ortho-carboranes and their dianions. J. Am. Chem. Soc. 127 (39), 13538-13547

[67] Llop, J. et al. (2002) Modulation of the C-C distance in disubstituted 1,2R-2-o-carboranes. Crystal structure of closo 1,2-(SPh)(2)-1,2-

C2B10H10. J. Organomet. Chem. 657 (1-2), 232-238

[68] Hawthorne, M.F. et al. (1968) Preparation and characterization of the (3)-1,2- and (3)-1,7-dicarbadodecahydroundecaborate $\left({ }^{-1}\right)$ ions. J. Am. Chem. Soc. 90 (4), 862-868

[69] Chen, W. et al. (1999) Synthesis and characterization of ortho-3- and meta-2-substituted carboranes through a boron-insertion reaction, including the structure of the product of a double-insertion reaction. Polyhedron 18 (12), 1725-1734

[70] Endou, H. and Kinai, Y. (1999) Amino Acid transporter molecule as a drug target. Nippon Yakugaku Zasshi 114, 11-16

[71] Varadarajan, A. and Hawthorne, M.F. (1991) Novel carboranyl amino acids and peptides; reagents for antibody modification and subsequent neutron-capture studies. Bioconjugate Chem. 2, 242-253

[72] Brattsev, V.A. and Stanko, V.I. (1969) Zh. Obshch. Khim. 39, 1175-1177

[73] Wyzlic, I.M. and Soloway, A.H. (1994) Carborane-containing amino acids as potential boron delivery agents for neutron capture therapy. In: Current Topics In The Chemistry Of Boron (Kabalka, G.W. ed) pp. 177180, Cambridge: Royal Society of Chemistry

[74] Sjöberg, S. et al. (1994) Carboranyl amino acids and amines with potential use in BNCT. In Current Topics In The Chemistry Of Boron (Kabalka, G.W. ed) pp. 173-176, Cambridge: Royal Society of Chemistry

[75] Radel, P.A. and Kahl, S.B. (1996) Enantioselective synthesis of L- and D-carboranylalanine. J. Org. Chem. 61 (14), 4582-4588

[76] Morris, G.M. et al. (1997) Central nervous system tolerance to boron neutron capture therapy with p-boronophenylalanine. Br. J. Cancer 76, 1623-1629

[77] Watanabe, T. et al. (2016) L-phenylalanine preloading reduces the $10 B(n, \alpha) 7 \mathrm{Li}$ dose to the normal brain by inhibiting the uptake of boronophenylalanine in boron neutron capture therapy for brain tumours. Cancer Letters 370 (1), 27-32

[78] Gabel, D. et al. (1993) Synthesis of S-alkyl and S-acyl derivatives of mercaptoundecahydrododeca-borate, a possible boron carrier for neutron capture therapy. Inorg. Chem. 32, 2276-2278

[79] Hasabelnaby, S. et al. (2012) Synthesis, chemical and enzymatic hydrolysis, and aqueous solubility of amino acid ester prodrugs of 3carboranyl thymidine analogs for boron neutron capture therapy of brain tumors. Eur. J. Med. Chem. 55 (1), 325-334

[80] Arner, E.S. and Eriksson, S. (1995) Mammalian deoxy ribonuclease kinases. Pharmacol. Ther. 67, 155-186

[81] Sivaev, I.B. et al. (2009) New approach to incorporation of boron in tumor-seeking molecules. Appl. Radiat. Isotopes 67, S91-S93 
[82] Semioshkin, A. A. et al. (2008) Cyclic oxonium derivatives of polyhedral boron hydrides and their synthetic applications. Dalton Trans. 8, 977-992

[83] Dembitsky, V.M. et al. (2004) Recent advances in the medicinal chemistry of alpha-aminoboronic acids, amine-carboxyboranes and their derivatives. Mini Rev. Med. Chem. 4 (9), 1001-1018

[84] Duthaler, R. O. (1994) Recent developments in the stereoselective synthesis of a-aminoacids. Tetrahedron 50, 1539- 1650

[85] Andrade, L. H. et al. (2010) Chemoenzymatic synthesis of boroncontaining chiral amines and amides. Tetrahedron: Asymmetry 21 (19), 2419-2424

[86] Ebdrup, S. et al. (2005) Structure-activity relationship for aryl and heteroaryl boronic acid inhibitors of hormone-sensitive lipase. Bioorg. Med. Chem. 13 (6), 2305-2312

[87] Lee, C. H. et al. (2009) New types of potential BNCT agents, ocarboranyl aminoalcohols. Tetrahedron Lett. 50 (24), 2960-2963

[88] Satapathya, R. et al. (2015) Glycoconjugates of polyhedral boron clusters. J. Organomet. Chem. 798 (1), 13-23

[89] Seeberger, P.H. and Werz, D.B. (2007) Synthesis and medical applications of oligosaccharides. Nature 446 (1), 1046-1051

[90] Roy, R. (1996) Syntheses and some applications of chemically defined multivalent glyco-conjugates. Curr. Opin. Struct. Biol. 6 (1), 692-700

[91] Yamazaki, N. et al. (2000) Endogenous lectins as targets for drug delivery. Adv. Drug Deliv. Rev. 43 (2-3), 225-244

[92] Patel, H. et al. (2013) Carborane-Appended Saccharides: Prime Candidates for Boron Neutron Capture Therapy (BNCT) Clinical Trials. Biochemical and Biophysical Journal of Neutron Therapy \& Cancer Treatments 1 (1), 15-21

[93] Tietze, L.F. and Bothe, U. (1998) ortho-Carboranyl glycosides of glucose, mannose, maltose and lactose for cancer treatment by boron neutron-capture therapy. Chem. Eur. J. 4, 1179-1183

[94] Ketz, H. et al. (1990) Synthesis of nido-carborane containing thioureas. Tetrahedron Lett. 31 (28), 4003-4006

[95] Bregadze, V. et al. (2011) Synthesis of conjugates of polyhedral boron compounds with tumour seeking molecules for neutron capture therapy. Appl. Radiat. Isot. 69 (12), 1774-1777

[96] Lesnikowski, Z.J. et al. (1999) Nucleic acids and nucleosides containing carboranes. J. Organomet. Chem. 581 (1-2), 156-169

[97] Tjarks, W. et al. (1992) Synthesis and in vitro evaluation of boronated uridine and glucose derivatives for boron neutron capture therapy. $J$. Med. Chem. 35, 1628-1633

[98] Laster, B.H. et al. (1990) Analysis of 5-iodo-2'-deoxyuridine incorporation in murine melanoma for photon activation therapy. Radiother. Oncol. 19 (2), 169-178

[99] Mourier, N.S. (1999) Enantioselective synthesis and biological evaluation of 5-o-carboranyl pyrimidine nucleosides. Bioorg. Med. Chem. 7 (12), 2759-2766

[100] Imamura, K. and Yamamoto, Y. (1997) Synthesis and in vitro evaluation of 5-closo and 5-nido-orthocarboranyluridines as boron carriers. Bull. Chem. Soc. Jpn. 70 (12), 3103-3110 
[101] Crossley, E.L. et al. (2011). Synthesis and cellular uptake of boron rich pyrazolopyrimidines: exploitation of the translocator protein for the efficient delivery of boron into human glioma cells. Chem.Comm. 47 (1), 12179-12181

[102] El-Hiti, G.A. and Abdel-Meqeed, M.F. (2005) Synthesis of glycosides containing quinazolin-4(3H)-one ring system. Heterocycles 65 (12), 3007-3041

[103]Zhuo, J.C. et al. (1999) Boron-Containing Heterocycles: Syntheses, Structures, and Properties of Benzoborauracils and a Benzoborauracil Nucleoside. J. Org. Chem. 64 (26), 9566-9574

[104] Genady, A.R. (2009) Promising carboranylquinazolines for boron neutron capture therapy: synthesis, characterization, and in vitro toxicity evaluation. Eur. J. Med. Chem. 44 (1), 409-416

[105] Lee, C.H. et al. (2008) Synthesis and characterization of polar functional group substituted mono- and bis-( o-carboranyl)-1,3,5-triazine derivatives. Tetrahedron Lett. 49 (1), 159-164

[106] Vicente, M.G.H. (2001) Porphyrin-based sensitizers in the detection and treatment of cancer: recent progress. Curr. Med. Chem. Anticancer Agents 1, 175-194

[107] Morin, C. (1994) The chemistry of boron analogues of biomolecules. Tetrahedron 44, 12521-12569

[108] Waldman, T. et al. (1997) Cell-cycle arrest versus cell death in cancer therapy. Natl. Med. 3, 1034-1036

[109] Dass, C.R. (2002) Vehicles for oligonucleotide delivery to tumors. J. Pharm. Pharmacol. 54 (1), 3-27

[110] Keefe, K.A. et al. (2001) Fluorescence detection of cervical intraepithelial neoplasia for photodynamic therapy with the topical agents 5-

aminolevulinic acid and benzoporphyrin-derivative monoacid ring. Am. J. Obstet. Gynecol. 184 (6), 1164-1169

[111] Dougherty, T.J. et al. (1998). Photodynamic therapy. J. Natl. Cancer Inst. 90 (12), 889-905

[112] Kreimann, E.L. et al. (2003). Biodistribution of a carborane-containing porphyrin as a targeting agent for Boron Neutron Capture Therapy of oral cancer in the hamster cheek pouch. Arch. Oral Biol. 48 (3), 223-232

[113] Polo, L. et al. (2002) Low-density lipoprotein receptors in the uptake of tumour photosensitizers by human and rat transformed fibroblasts. Int. J. Biochem. Cell Biol. 34 (1), 10-23

[114] Callahan, D.E. et al. (1999) Boronated protoporphyrin (BOPP): localization in lysosomes of the human glioma cell line SF-767 with uptake modulated by lipoprotein levels. Int. J. Radiat. Oncol. Biol. Phys. 45 (3), 761-771

[115] Easson, M.W. et al. (2008) Synthesis and in vitro properties of trimethylamine- and phosphonate-substituted carboranylporphyrins for application in BNCT. Bioorg. Med. Chem. 16 (6), 3191-3208

[116] Haushalter, R.C. et al. (1981) The preparation and characterization of several meso-tetracarboranylporphyrins. J. Am. Chem. Soc. 103 (10), 2620-2627

[117] Pietrangeli, D. et al. (2013) Carboranyl-porphyrazines and derivatives for boron neutron capture therapy: From synthesis to in vitro tests. Coord. Chem. Rev. 257, 2213-2231 
[118] Hill, J.S. et al. (1992) Selective tumor uptake of a boronated porphyrin in an animal model of cerebral glioma. Proc. Natl. Acad. Sci. USA 89, 1785-1789

[119] Ceberg, C.P. et al. (1995) A comparative study on the pharmacokinetics and biodistribution of boronated porphyrin (BOPP) and sulfhydryl boron hydride (BSH) in the RG2 rat glioma model. J. Neurosurg. 83, 86-92

[120] Munday, A.D. et al. (1996) Mitochondria are the functional intracellular target for a photosensitizing boronated porphyrin. Biochim. Biophys. Acta 1311, 1-4

[121] Miura, M. et al. (1992) Biodistribution and toxicity of 2,4-divinyl-nido-ocarboranyldeuteroporphyrin IX in mice. Biochem. Pharmacol. 43, 467476

[122] Miura, M. et al. (1998) Evaluation of carborane-containing porphyrins as a tumor-targeting agents for boron neutron-capture therapy. $\mathrm{Br}$. J. Radiol. 71, 773-781

[123] Fabris, C. et al. (2007) Tumour-localizing and -photosensitising properties of meso-tetra(4-nido-carboranylphenyl)porphyrin $\left(\mathrm{H}_{2} \mathrm{TCP}\right)$. J. Photochem. Photobiol. B: Biology 89, 131-138

[124] Tsaryova, O. et al. (2005) Synthesis of new carboran-based phthalocyanines and study of their activities in the photooxidation of citronellol. J. Porphyrins Phthalocyanines 9, 268-274

[125] Kahl, S.B. and Li, J. (1996) Synthesis and characterization of a boronated metallophthalocyanine for boron neutron capture therapy. Inorg. Chem. 35 (13), 3878-3880

[126] Weissig, V. et al. (2004) Mitochondrial pharmaceutics. Mitochondrion 3, 229-244

[127] Weissig, V. and Torchilin, V. (2001) Cationic bolasomes with delocalized charge centers as mitochondria-specific DNA delivery system. Adv. Drug Delivery Rev. 49, 127-149

[128]Burns, R.J. and Murphy, M.P. (1997) Labeling of mitochondrial proteins in living cells by the thiol probe thiobutyltriphenylphosphonium bromide. Arch. Biochem. Biophys. 339, 33-39

[129] Adams, D.M. et al. (2000) Comparative in vitro evaluation of Dequalinium B, a new boron carrier for neutron capture therapy (NCT). Anticancer Res. 20, 3395-3402

[130] Calabrese, G. et al. (2008) Carborane-based derivatives of delocalised lipophilic cations for boron neutron capture therapy: synthesis and preliminary in vitro evaluation. J. Mater. Chem. 18, 4864-4871

[131] loppolo, J.A. et al. (2009) Water-soluble phosphonium salts containing 1,12-dicarba-closo-dodecaborane(12). Tetrahedron Lett. 50, 6457-6461

[132] Tseligka, E.D. et al. (2016) Pharmacological development of targetspecific delocalized lipophilic cation-functionalized carboranes for cancer therapy. Pharm. Res. 33(8), 1945-1958

[133] loppolo, J.A. et al. (2013) Remarkable cage deboronation and rearrangement of a closo-1,12-dicarbadodecaborane to form a neutral nido-7,9-dicarbaundecaborane. Chem. Commun. 49, 3312-3314

[134] Chen, W. et al. (2000) Synthesis and characterization of water-soluble boron-substituted ortho-carborane derivatives. Acad. Sci. Ser. Ilc: Chim. 3, 223-229 
[135] Fairchild, R.G. et al. (1982) Chlorpromazine distribution in hamsters and mice bearing transplantable melanoma. Cancer Res. 42, 556-562

[136] Nakagawa, T. and Aono, K. (1976) Syntheses of chlorpromazine undecahydrododecaborate and nonahydrodecaborate - promising agents for neutron capture therapy of malignant melanoma. Chem. Pharm. Bull. (Tokyo) 24, 778-781

[137] Alarm, F. et al. (1989) In Strahlentherapie Und Onkologie (Scherer, E. Ed) p. 121, Urban \& Vogel: Munich, Germany

[138] Wyzlic, I.M. et al. (1996) Synthesis of carboranyl amino acids, hydantoins, and barbiturates. Inorg. Chem. 35 (16), 4541-4547

[139] Bregadze, V.I. et al. (1978) The synthesis of the carboranyl derivatives of main groups IV-VI elements with boron-element bonds. J. Organomet. Chem. 157 (1), C1-C2

[140] Gielen, M. et al. (1995) Synthesis, characterization and in vitro antitumour activity of novel organotin derivatives of 1,2- and 1,7-dicarbacloso-dodecaboranes. Met.-Based Drugs 2 (1), 37-42

[141] Tiekink, E.R.T. et al. (1997) X-ray structure and in vitro anti-tumoural activity of the dimeric bis[(2-phenyl-1,2-dicarba-closo-dodecaborane-1carboxylato)-di- $n$-butyltin] oxide. Met.-Based Drugs 4 (2), 75-80

[142] Bregadze, V.I. et al. (2003) Synthesis, characterization, x-ray crystal structure and in vitro antitumour activity of bis(1,2-dicarba-closododecaborane-9-carboxylato)di- $n$-butyltin. Appl. Organomet. Chem. 17 (6-7), 453-457

[143] Woodhouse, S.L. et al. (2005) Synthesis and anti-cancer activity of dinuclear platinum(II) complexes containing bis(thioalkyl)dicarba-closododecaborane(12) ligands. Dalton Trans. 17, 2827-2829

[144] Todd, J.A. et al. (2005) (2,2':6',2' '-terpyridine)platinum(II) complexes containing (thioalkyl)dicarba-closo-dodecaborane(12) ligands. Inorg. Chem. 44 (18), 6401-6408

[145] Protti, N. et al. (2015) Evaluation of the dose enhancement of combined ${ }^{10} \mathrm{~B}+{ }^{157} \mathrm{Gd}$ neutron capture therapy (NCT). Radiat. Prot. Dosimetry 166 (1-4), 369-373 